\title{
IMPLEMENTASI KERANGKA KERJA ZACHMAN DALAM \\ PERANCANGAN ARSITEKTUR SISTEM INFORMASI DAN TEKNOLOGI INFORMASI PERUSAHAAN
}

\author{
Muksin Wijaya \\ Sekolah Tinggi Manajemen Informatika dan Komputer LIKMI \\ Jl. Ir. Juanda 96 Bandung 40132 \\ muksin.wj@gmail.com
}

\begin{abstract}
ABSTRAK
Membangun arsitektur sistem informasi perusahaan adalah salah satu hal penting dari sekian perencanaan strategis perusahaan yang perlu dipertimbangkan oleh perusahaan, terutama implementasi pada perusahaan yang siap berkembang. Pada perusahaan yang siap berkembang, penyederhanaan proses bisnis penting dilakukan agar dapat diselaraskan dengan keadaan dan kondisi perusahaan, dan untuk itu perlu suatu kerangka kerja yang dapat diterapkan untuk mencapai tujuan tersebut. Kerangka kerja perusahaan yang dimaksud adalah sebagai kerangka kerja yang memberikan arahan berbagai aturan dan standar serta tatanan tertentu dalam membantu perusahaan dalam menemukan hal-hal yang sesuai dan pas untuk diimplementasikan sebagai bagian dari strategi pengembangan perusahaan.

Dari sekian model kerangka kerja yang ada, diantaranya terdapat model kerangka kerja Zachman (Zachman Framework) yang dapat menjadi alternatif untuk dipakai dalam upaya perusahaan untuk menyusun strategi bisnisnya, kerangka kerja ini terdiri atas langkahlangkah yang sistematis, mudah dipahami dan dapat pula dijadikan sebagai kendali bagi perusahaan dalam mengembangkan lebih lanjut strategi bisnisnya.
\end{abstract}

Kata Kunci: bisnis, strategi perusahaan, kerangka kerja perusahaan, Zachman Framework

\section{PEMAHAMAN ARSITEKTUR PERUSAHAAN}

Arsitektur perusahaan (enterprise) yang dimaksudkan merupakan perpaduan dua kata yang terangkai menjadi satu kesatuan pemahaman istilah, yaitu enterprise dan arsitektur.

\subsection{Definisi Enterprise}

Kata enterprise secara umum dapat diartikan sebagai suatu organisasi atau perusahaan, menurut kamus bahasa Inggris - Indonesia (1996:215) oleh Echols dan Shadily, kata enterprise berarti perusahaan atau firma persekutuan dan rombongan.

\subsection{Definisi Arsitektur}

Menurut Kurniawan, arsitektur pada dasarnya menggambarkan bentuk konstruksi sistem yang akan diwujudkan dalam sebuah model yang dilihat dari beberapa sudut pandang. (Kurniawan, 2011).

Menurut Minoli, definisi dari arsitektur merupakan sistem yang fundamental dari organisasi, yang menunjukan saling keterhubungan antara komponen dengan lingkungan dan prinsip utama mengembangkan design dari suatu sistem perusahan. (Minoli, 2008) 


\subsection{Definisi Arsitektur Enterprise}

Enterprise architecture (EA) adalah deskripsi dari misi stakeholder yang di dalamnya termasuk informasi, fungsionalitas atau kegunaan, lokasi organisasi dan parameter kinerja. Enterprise Architecture pada perusahaan akan pada umumnya akan merujuk pada pencitraan rencana perusahaan untuk mengembangkan sebuah sistem atau sekumpulan sistem (Hadiana, 2016).

Dalam suatu Enterprise Architecture terdapat komponen dari kerangka kerjanya, berikut deskripsi lebih rinci mengenai komponen-komponen yang ada di dalam Enterprise Architecture pada setiap tingkat kerangka kerjanya.

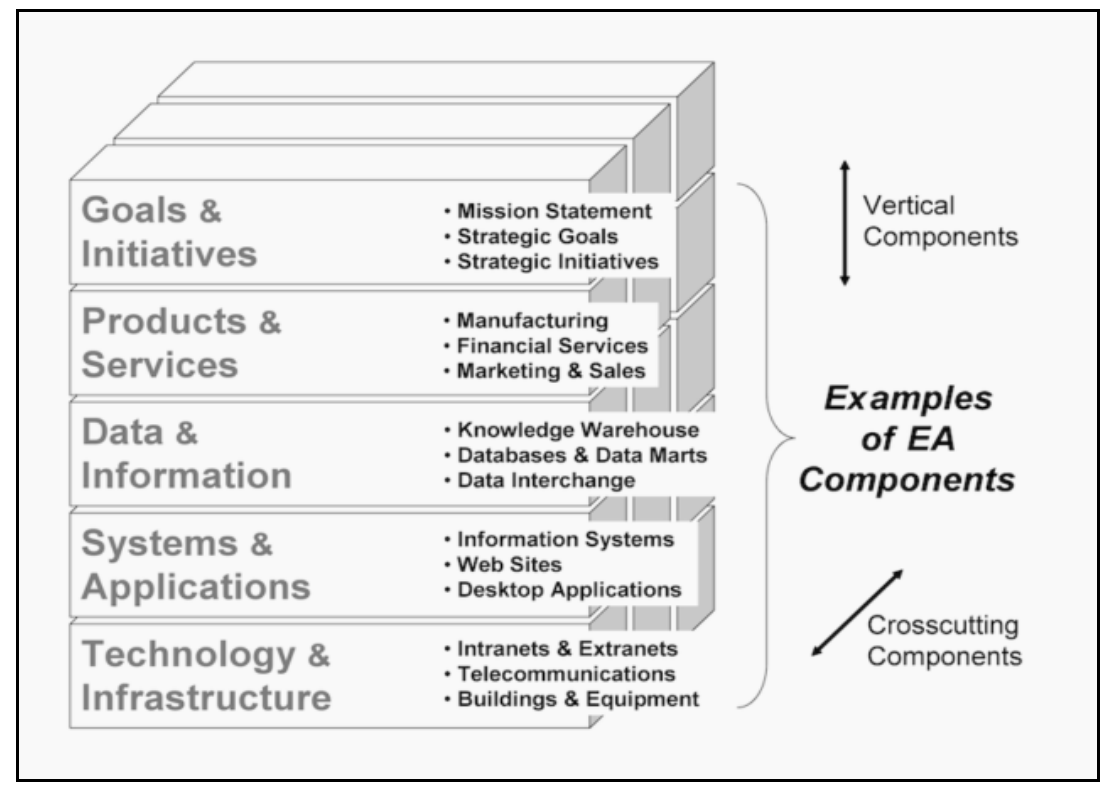

Gambar 1

Komponen Enterprise Architecture (Alexandria, 2018)

a. Sasaran dan Inisiatif Strategi (Goal and Initiatives)

Tingkat atas dari kerangka kerja EA mengidentifikasi arah strategis, tujuan, dan inisiatif dari perusahaan dan memberikan gambaran yang jelas terhadap kontribusi yang akan diberikan TI dalam mencapai tujuan tersebut. Perencanaan strategis dimulai dengan pernyataan yang jelas tentang tujuan perusahaan dan atau misi, dilengkapi dengan pernyataan singkat tentang visi untuk sukses. Hal ini diikuti dengan Deskripsi dari arah strategis dengan perusahaan, kejadian yang bisa terjadi, dan juga strategi bersaing yang akan memastikan tidak hanya dapat bertahan, namun keberhasilan yang telah ditentukan perusahaan. Seluruh pernyataan ini didukung oleh proses identifikasi tujuan dan inisiatif yang mencakup hasil yang terukur dan penilaian kinerja (Bernard, 2012:112).

b. Produk dan Layanan Bisnis (Products and Services)

Tingkat kedua dari kerangka kerja EA mengidentifikasi layanan produk bisnis perusahaan dan kontribusi teknologi untuk mendukung proses tersebut. Istilah layanan bisnis digunakan untuk menyatakan proses dan prosedur yang dilaksanakan untuk mencapai misi dan tujuan perusahaan, apakah itu untuk bersaing pada sektor swasta, melakukan pelayanan publik, mendidik, memberikan layanan kesehatan, atau memberikan kemampuan pertahanan. (Bernard, 2012:112). 
c. Data dan Informasi (Data and Information)

Tujuan sekunder arsitektur adalah mengoptimalkan data dan pertukaran informasi. Tingkat ketiga dari kerangka kerja EA dimaksudkan untuk mendokumentasikan bagaimana informasi saat ini sedang digunakan oleh perusahaan dan bagaimana arus informasi masa depan akan terlihat. Tingkat ini dapat tercermin melalui dokumen Strategi TI yang mengikat ke dalam rencana strategis perusahaan dan/atau rencana bisnis. Tujuan dari strategi TI adalah untuk membentuk suatu pendekatan tingkat tinggi untuk mengumpulkan, menyimpan, mengubah, dan menyebarkan informasi pada seluruh perusahaan. Penggunaan konsep-konsep seperti manajemen pengetahuan, data mining, gudang informasi dan portal web dapat diatur melalui strategi TI (Bernard, 2012:113). Rancangan dan fungsi basis data ada seluruh perusahaan juga didokumentasikan pada tingkat ini sebagai standar format data, kamus data, dan repository kumpulan objek yang dapat digunakan kembali.

d. Sistem dan Aplikasi (Systems and Applications)

Tingkat keempat kerangka kerja EA dimaksudkan untuk mengorganisasikan dan mendokumentasikan kelompok sistem informasi saat ini, dan aplikasi yang digunakan oleh perusahaan untuk memberikan kemampuan IT. Tergantung pada perubahan pada kerangka kerja EA tingkat di atasnya (layanan bisnis atau arus informasi) mungkin direncanakan perubahan sistem atau aplikasi yang harus tercermin dalam pandangan arsitektur masa depan (Bernard, 2012:113). Area sistem dan aplikasi dalam kerangka kerja EA ini juga merupakan komponen dengan fitur yang menonjol dalam arsitektur berorientasi layanan, sebagai aplikasi komersial semakin meningkat beroperasi yang tersedia bagi perusahaan (contoh: standar industri J2EE dan .NET). Aplikasi modular yang besar dapat menangani seluruh lini bisnis dan/atau fungsi back office (contoh: sistem keuangan, sistem pengendali manufaktur, dan sistem pengelolaan rantai pasokan). Sistem yang besar ini sering disebut sebagai ERP (Enterprise Resource Planning). Pendekatan modular pada sistem ERP mencerminkan strategi pasang pakai yang dapat diadopsi oleh perusahaan pada level ini dalam kerangka kerja EA untuk meningkatkan interoperabilitas dan penurunan biaya.

e. Jaringan dan Infrastruktur (Networks and Infrastructure)

Jaringan dan infrastruktur adalah tulang punggung dari arsitektur. Tingkat kelima yang merupakan bagian paling dasar dari kerangka kerja EA, merupakan tingkat paling bawah, dimaksudkan untuk mengatur dan mendokumentasikan pandangan saat ini dan masa depan jaringan suara, data, dan video yang digunakan oleh perusahaan pada komputer pusat sistem (host), aplikasi, situs web, dan database. Tingkat ini juga mendokumentasikan infrastruktur perusahaan (misalnya bangunan, ruang server, peralatan modal). Local Area Network (LAN), Wide Area Network (WAN), System Application Network (SAN), intranet, extranet, Jaringan Nirkabel semua terorganisir dan didokumentasikan pada tingkat ini sehingga desain yang efisien dapat diimplementasikan melalui arsitektur masa depan yang mengurangi duplikasi, meningkatkan efisiensi biaya dan kinerja, dan mempromosikan ketersediaan dan ketahanan hidup (Bernard 2012:114). Seringkali sebuah perusahaan akan menentukan bahwa kemampuan TI tertentu adalah bersifat kritis terhadap kesuksesan perusahaan, dan arsitektur dalam area ini harus mencerminkan sumber daya yang berlapis (redundant) pada lokasi yang berbeda sedemikian sehingga kemampuan ini dapat terus tersedia jika sumber daya utama tidak tersedia.

\section{ENTERPRISE ARCHITECTURE PLANNING (EAP)}

Selanjutnya dalam perancangan arsitektur perusahaan atau Enterprise arsitektur 
perlu dilakukan suatu rencana yang matang yang kemudian kina kenal dengan istilah Perencanaan Arsitektur Perusahaan (Enterprise Architecture Planning), yaitu suatu proses yang dilakukan perusahaan dalam mendefinisikan arsitekturnya dalam penggunaan informasi yang berfungsi untuk menjalankan bisnis dan rencana untuk implementasinya. Tujuan akhirnya adalah terpenuhinya kebutuhan data dari pihak manajemen.

Perencanaan arsitektur perusahaanberfokus pada pendefinisian arsitektur data, aplikasi, dan teknologi untuk perusahaan secara keseluruhan, dalam hal ini kerangka Zachman dapat membantu perusahaan untuk pencapai tujuan ini. Kerangka kerja Zachman sebagai kerangka berfikir konseptualnya.

\section{KERANGKA KERJA ZACHMAN (ZACHMAN FRAMEWORK)}

Dalam buku Zachman Framework for Enterprise Architecture yang diterbitkan John Zachman pada tahun 1987, Zachman menuliskan: "peningkatan cakupan desain dan tingkat kompleksitas implementasi sistem informasi menuntut perusahaan untuk melangkah berdasarkan beberapa konstruksi arsitektur yang logis." Kerangka Zachman didasarkan pada prinsip-prinsip arsitektur klasik yang membentuk persamaan umum, dan seperangkat perspektif yang umum untuk menggambarkan sistem perusahaan yang kompleks. Kerangka kerja ini tidak memberikan panduan mengenai urutan, proses, atau implementasi, namun berfokus pada memastikan bahwa semua pandangan telah mapan, memastikan sistem yang lengkap terlepas dari urutan kemunculan nya. Kerangka Zachman memiliki enam perspektif atau pandangan: Perencana, Pemilik, Perancang, Pembangun, Subkontraktor, dan Pengguna. Penjelasannya adalah sebagai berikut:

a. Planner/ Perencana: yang menetapkan objek dalam pembahasan latar belakang, lingkup, dan tujuan enterprise.

b. Owner/Pemilik: penerima atau pemakai produk/jasa akhir dari enterprise.

c. Designer/Perancang: perantara antara apa yang diinginkan (pemilik) dan apa yang dapat dicapai secara teknis dan fisik.

d. Builder/ Pembangun: pengawas/pengatur dalam menghasilkan produk/jasa akhir.

e. Subkontraktor: bertanggung jawab membangun dan merakit bagian-bagian dari produk/jasa akhir.

f. Functioning enterprise: wujud nyata dari produk/jasa akhir.

Karakteristik Zachman Framework:

a. Mengategorikan deliverables dari EA

b. Kegunaan EA yang terbatas

c. Banyak diadopsi di seluruh dunia

d. Perspektif view yang kurang menyeluruh

e. Merupakan tool untuk perencanaan

Banyak organisasi tertarik untuk membangun arsitektur enterprise mereka dengan menggunakan framework Zachman. Mereka berharap dapat memecahkan masalah ketidaksesuaian antara proses bisnis dan sistem informasi seiring dengan memperoleh tingkat interoperabilitas dan fleksibilitas yang diinginkan di lingkungan TI mereka. Namun, dalam kebanyakan kasus kerangka kerja Zachman tetap sebagai kerangka konseptual lebih dari yang pragmatis. Hal ini menyebabkan keraguan yang serius mengenai apakah perusahaan dapat memuaskan motivasi penggunaan kerangka kerja Zachman. 


\begin{tabular}{|c|c|c|c|c|c|c|}
\hline & $\begin{array}{l}\text { What? } \\
\text { (Data) }\end{array}$ & $\begin{array}{l}\text { How? } \\
\text { (Function) }\end{array}$ & $\begin{array}{l}\text { Where? } \\
\text { (Location) }\end{array}$ & $\begin{array}{l}\text { Who? } \\
\text { (People) }\end{array}$ & $\begin{array}{l}\text { When? } \\
\text { (Time) }\end{array}$ & $\begin{array}{l}\text { Why? } \\
\text { (Motivation) }\end{array}$ \\
\hline $\begin{array}{l}\text { Business } \\
\text { Concept } \\
\text { Planner }\end{array}$ & $\begin{array}{l}\text { Inventory } \\
\text { Identification }\end{array}$ & $\begin{array}{l}\text { Process } \\
\text { Identification }\end{array}$ & $\begin{array}{l}\text { Distribution } \\
\text { Identification }\end{array}$ & $\begin{array}{l}\text { Responsibility } \\
\text { Identification }\end{array}$ & $\begin{array}{l}\text { Timing } \\
\text { Identification }\end{array}$ & $\begin{array}{l}\text { Motivation } \\
\text { Identification }\end{array}$ \\
\hline $\begin{array}{l}\text { Business } \\
\text { Concept } \\
\text { Owner }\end{array}$ & $\begin{array}{l}\text { Inventory } \\
\text { Definition }\end{array}$ & $\begin{array}{l}\text { Process } \\
\text { Definition }\end{array}$ & $\begin{array}{l}\text { Distribution } \\
\text { Definition }\end{array}$ & $\begin{array}{l}\text { Responsibility } \\
\text { Definition }\end{array}$ & $\begin{array}{l}\text { Timing } \\
\text { Definition }\end{array}$ & $\begin{array}{l}\text { Motivation } \\
\text { Definition }\end{array}$ \\
\hline $\begin{array}{l}\text { Business } \\
\text { Logic } \\
\text { Designer }\end{array}$ & $\begin{array}{l}\text { Inventory } \\
\text { Representation }\end{array}$ & $\begin{array}{l}\text { Process } \\
\text { Representation }\end{array}$ & $\begin{array}{l}\text { Distribution } \\
\text { Representation }\end{array}$ & $\begin{array}{l}\text { Responsibility } \\
\text { Representation }\end{array}$ & $\begin{array}{l}\text { Timing } \\
\text { Representation }\end{array}$ & $\begin{array}{l}\text { Motivation } \\
\text { Representation }\end{array}$ \\
\hline $\begin{array}{l}\text { Business } \\
\text { Physics } \\
\text { Builder }\end{array}$ & $\begin{array}{l}\text { Inventory } \\
\text { Specification }\end{array}$ & $\begin{array}{l}\text { Process } \\
\text { Specification }\end{array}$ & $\begin{array}{l}\text { Distribution } \\
\text { Specification }\end{array}$ & $\begin{array}{l}\text { Responsibility } \\
\text { Specification }\end{array}$ & $\begin{array}{l}\text { Timing } \\
\text { Specification }\end{array}$ & $\begin{array}{l}\text { Motivation } \\
\text { Specification }\end{array}$ \\
\hline $\begin{array}{l}\text { Business } \\
\text { Component } \\
\text { Implementer }\end{array}$ & $\begin{array}{l}\text { Inventory } \\
\text { Configuration }\end{array}$ & $\begin{array}{l}\text { Process } \\
\text { Configuration }\end{array}$ & $\begin{array}{l}\text { Distribution } \\
\text { Configuration }\end{array}$ & $\begin{array}{l}\text { Responsibility } \\
\text { Configuration }\end{array}$ & $\begin{array}{l}\text { Timing } \\
\text { Configuration }\end{array}$ & $\begin{array}{l}\text { Motivation } \\
\text { Configuration }\end{array}$ \\
\hline User & $\begin{array}{l}\text { Inventory } \\
\text { Instantiations }\end{array}$ & $\begin{array}{l}\text { Process } \\
\text { Instantiations }\end{array}$ & $\begin{array}{l}\text { Distribution } \\
\text { Instantiations }\end{array}$ & $\begin{array}{l}\text { Responsibility } \\
\text { Instantiations }\end{array}$ & $\begin{array}{l}\text { Timing } \\
\text { Instantiations }\end{array}$ & $\begin{array}{l}\text { Motivation } \\
\text { Instantiations }\end{array}$ \\
\hline
\end{tabular}

Gambar 2

\section{Zachman Framework}

Konsep dari Framework Zachman adalah bahwa hal kompleks yang sama dapat digambarkan untuk tujuan yang berbeda dengan cara yang berbeda menggunakan berbagai jenis Deskripsi. Setiap baris dalam Zachman framework mewakili perspektif tertentu. Sebuah baris atas atau perspektif tidak selalu memiliki pemahaman yang lebih komprehensif dari perspektif yang lebih rendah. Dalam Zachman framework tahun 1997 baris dijelaskan dari sudut pandang Planner's view (scope), Owner's view (enterprise atau model bisnis), Designer's view (Information System model), Builder's view. Ide dasar dibalik Framework Zachman adalah bahwa hal kompleks yang sama dapat digambarkan untuk tujuan yang berbeda dengan cara yang berbeda menggunakan berbagai jenis Deskripsi. Sebuah baris atas atau perspektif tidak selalu memiliki pemahaman yang lebih komprehensif dari perspektif yang lebih rendah.

Kolom Zachman framework dapat dijelaskan sebagai berikut: masing-masing perspektif memfokuskan perhatian pada pertanyaan mendasar yang sama, jawaban pertanyaan-pertanyaan dari sudut pandang itu, menciptakan representasi deskriptif yang berbeda (yaitu model), yang menerjemahkan dari perspektif yang lebih tinggi ke yang lebih rendah. Kolom Zachman framework adalah sebagai berikut :

a. WHAT

Objek : Data

Fokus : Hubungan antar entitas

Deskripsi :

Kolom What menguraikan informasi organisasi yaitu: Data. Data yang diuraikan merupakan data yang memiliki relasi dengan data lainnya. (Contohnya: data kode pos yang menjadi bermanfaat ketika digunakan bersama dengan data alamat).

b. HOW

Objek : Proses dan fungsi 
Fokus : Pernyataan fungsi / input dan output

Deskripsi :

Kolom How disediakan untuk mendeskripsikan fungsionalitas dari sistem informasi. Bagaimana organisasi bekerja? Bagaimana memenuhi pesanan? Atau bagaimana data digunakan sebagai uraian proses/output.

c. WHERE

Objek : Jaringan

Fokus : Nodes, Links

Deskripsi :

Kolom Where menunjukkan lokasi kerja dari organisasi. Memungkinkan organisasi berada di satu bangunan, beberapa kantor atau di sekeliling dunia. Jika semua lokasi organisasi saling terkoneksi maka diperlukan identifikasi terlebih dahulu.

d. $W H O$

Objek : Sumber daya manusia

Fokus : Pekerjaan, peran dan tanggung jawab

Deskripsi :

Kolom Who membahas mengenai alokasi sumber daya manusia serta struktur dan tanggung jawab dalam organisasi. Kolom Who menguraikan orang-orang dalam perusahaan dan pekerjaan (atau produk) kinerja pegawai.

e. WHEN

Objek : Waktu

Fokus : Siklus waktu

Deskripsi :

Kolom When digunakan untuk mendisain event-event yang memiliki relasi dalam membangun kriteria kinerja dan tingkat kualitatif untuk sumber daya organisasi.

f. $W H Y$

Objek : Motivasi

Fokus : Maksud dan tujuan organisasi

Deskripsi :

Kolom Why menguraikan tentang motivasi, tujuan akhir yang ingin dicapai beserta strategi/metode yang digunakan organisasi.

\section{KESIMPULAN}

Pada perusahaan yang siap berkembang, penyederhanaan proses bisnis penting dilakukan agar dapat diselaraskan dengan keadaan dan kondisi perusahaan, dan untuk itu perlu suatu kerangka kerja yang dapat diterapkan untuk mencapai tujuan tersebut. Kerangka kerja ini memberikan arahan berbagai aturan dan standar serta tatanan tertentu dalam membantu perusahaan dalam menemukan hal-hal yang sesuai dan pas untuk diimplementasikan sebagai bagian dari strategi pengembangan perusahaan.

Konsep dari Framework Zachman adalah bahwa hal kompleks yang sama dapat digambarkan untuk tujuan yang berbeda dengan cara yang berbeda menggunakan berbagai jenis Deskripsi. Framework Zachman dapat menjadi alternatif untuk dipakai dalam upaya perusahaan untuk menyusun strategi bisnisnya. Kerangka kerja ini terdiri atas langkahlangkah yang sistematis, mudah dipahami dan dapat pula dijadikan sebagai kendali bagi perusahaan dalam mengembangkan lebih lanjut strategi bisnisnya. 


\section{DAFTAR PUSTAKA}

[1] Alexandria, J. (2018). Komponen di dalam Enterprise Architecture. Retrieved 9 11, 2020.

[2] Bernard, S. A. (2012). An Introduction to Enterprise Architecture. 3th Edition. Bloomington: AuthorHouse.

[3] Irfano, R., \& Andry, J. F. (2017). Perancangan Architecture Menggunakan Zachman Framework (Studi Kasus: PT. Vivamas Adipratama).

[4] Minoli, D. (2008). Enterprise architecture A to Z : frameworks, business process modeling, SOA, New York: CRC Press 